\title{
Is an Impacted Morselized Graft in a Cage an Alternative for Reconstructing Segmental Diaphyseal Defects?
}

\author{
Pieter H. J. Bullens MD, H. W. Bart Schreuder MD, PhD, \\ Maarten C. de Waal Malefijt MD, Nico Verdonschot PhD, \\ Pieter Buma PhD
}

Received: 29 December 2007/ Accepted: 15 December 2008/Published online: 14 January 2009

(C) The Author(s) 2009. This article is published with open access at Springerlink.com

\begin{abstract}
Large diaphyseal bone defects often are reconstructed with large structural allografts but these are prone to major complications. We therefore asked whether impacted morselized bone graft could be an alternative for a massive structural graft in reconstructing large diaphyseal bone defects. Defects in the femora of goats were reconstructed using a cage filled with firmly impacted morselized allograft or with a structural cortical autograft ( $\mathrm{n}=6$ in both groups). All reconstructions were stabilized with an intramedullary nail. The goats were allowed full weightbearing. In all reconstructions, the grafts united radiographically. Mechanical torsion strength of the femur with the cage and structural cortical graft reconstructions were $66.6 \%$ and $60.3 \%$, respectively, as compared with the contralateral femurs after 6 months. Histologically, the impacted morselized graft was replaced completely by new viable bone. In the structural graft group, a mixture of new and necrotic bone was present. Incorporation of the impacted graft into new viable bone suggests this type of reconstruction may be safer than reconstruction with a structural graft in which creeping substitution results in a mixture of viable and necrotic bone that can fracture. The data suggest that a cage
\end{abstract}

Each author certifies that he or she has no commercial associations (eg, consultancies, stock ownership, equity interest, patent/licensing arrangements, etc) that might pose a conflict of interest in connection with the submitted article.

P. H. J. Bullens, N. Verdonschot, P. Buma ( $($ )

Orthopedic Research Laboratory, Radboud University Nijmegen

Medical Centre, PO Box 9101, 6500 HB Nijmegen,

The Netherlands

e-mail: P.Buma@orthop.umcn.nl

P. H. J. Bullens, H. W. Bart Schreuder, M. C. de Waal Malefijt Department of Orthopedic Surgery, Radboud University Nijmegen Medical Centre, Nijmegen, The Netherlands filled with a loaded morselized graft could be an alternative for the massive cortical graft in reconstruction of large diaphyseal defects in an animal model.

\section{Introduction}

Large diaphyseal bone defects can be the result of trauma, osteomyelitis, or resection of bone tumors. Structural allografts are used in reconstruction of these bone defects. However, massive cortical allografts are associated with problems like nonunion, infection, and fatigue fractures $[2,11,20]$. An alternative method for fixation and regeneration of new bone in large defects is distraction osteogenesis using external fixation systems. However, this method is technically demanding and has a high complication rate (as much as two to 3.2 difficulties per patient) [13, 18, 19]. Numerous complications are relatively harmless such as pin tract infections (37\%-100\%) $[18,19]$ and joint stiffness (39\%) [18]. Other more severe complications are persistent pain (17\%) [18], fractures at the docking site (21\%) [9], limb-length discrepancy $(100 \%)$ [13], and amputations $(10 \%-11 \%)[18,19]$. Another disadvantage is the duration of treatment with several additional operative procedures, which requires considerable patient compliance $[12,18,19]$. Therefore, alternative procedures for repair of these large defects are needed.

Impaction bone grafting in revision arthroplasty is effective for repair of large bone defects with survival rates of $90 \%$ to $94 \%$ after 10 to 18 years followup [25, 27]. With large segmental defects, containment of the impacted bone graft is achieved by metal meshes, which are placed around the original location of the missing bone. The initial stability of the morselized graft is related to the density of the graft, reinforcing the need for firm impaction [4, 14]. 
This procedure has been used in numerous animal studies in the acetabulum and femur $[1,5]$ and is performed routinely in revisions of failed hip implants [22, 23, 26, 27]. Histologic analysis of retrieved specimens has revealed remodeling concomitant with gradual ingrowth of the graft, which is mandatory for long-term survival [7, 14, 31]. Initially, cortical grafts obviously have better mechanical properties as compared with morselized bone grafts. However, from a biologic perspective, ingrowth of impacted morselized allograft is superior to structural cortical allograft, which might result in higher incorporation and union rate and thereby superior long-term characteristics [28, 29].

Based on the results with impaction grafting for revision hip arthroplasty, we wondered whether morselized bone graft in a cage could be an alternative for a massive cortical graft in segmental diaphyseal defect reconstructions. Using such a goat model, we asked (1) if the goats regained a normal walking pattern; (2) if the reconstructions healed radiographically; (3) if the strengths of the two reconstruction methods (morselized and cortical grafts) differed in a torsion test; and (4) if the histologic appearance of the two graft types differed after incorporation.

\section{Materials and Methods}

We used 12 Dutch milk goats with 24 femurs (female, Capra Hircus Sana; weight range, 57-64 kg), dividing the 24 femurs into four groups of six femurs (cage reconstruction, cortical graft reconstruction, nonoperated side of the cage group, nonoperated side of the cortical group). We performed a power analysis based on the relevant variable torsional strength. The variation was set at $8.75 \mathrm{Nm}$, which was based on results of a pilot study and on previous experiments in the femur of goats [15]. The difference in torsional strengths between groups was set at $15 \mathrm{Nm}$, which is approximately $15 \%$ of the normal strength. The relevance of this difference for prediction of fracture risk is difficult because in the test animals, the central nail is still in situ during daily activity, which will contribute substantially to the torsional strength. The expected variation in a group and the difference between groups led to a group size of six goats in this study. All animals were skeletally mature.

The cage was a stainless steel mesh (X-Change system; Stryker Howmedica, Newbury, UK) that was cut to a height of $4.5 \mathrm{~cm}$ and folded into a cylinder with a diameter of $22 \mathrm{~mm}$ (average diameter of the shaft of a goat femur). This mesh was fixed with three cerclage wires to stabilize the cylinder. We harvested the morselized allograft used to fill the cages from the donor goats' sternum. The cancellous bone was morselized by hand using a rongeur that produced small (1-3 $\mathrm{mm}$ ), pure cancellous bone chips. We subsequently processed the bone chips in a Noviomagus bone mill (Spierings Medische Techniek, Nijmegen, The Netherlands) with the smallest rasping blade leading to a particle size of approximately $2 \mathrm{~mm}$. Each batch of cancellous allograft was washed using $2 \mathrm{~L}$ of saline with a pulse lavage jet system (Stryker Howmedica). Each cage was filled with five layers of morselized bone graft. The total amount of bone graft used in each reconstruction was approximately $28 \mathrm{~g}$. After each layer, 10 standardized impactions were made with a mass of $1.5 \mathrm{~kg}$ that was dropped from a height of $35 \mathrm{~cm}$. The last layer was followed by 40 similar impactions, after which the impacted graft in the cage had a height of $35 \mathrm{~mm}$. At each end of the $45-\mathrm{mm}$ high cages, $5 \mathrm{~mm}$ of the cage was left unfilled on both sides, which enabled the host bone to slide into the cage (Fig. 1). During impaction, a central nail was positioned in the cage to reserve space for introduction of the intramedullary nail in the animals.

Under general anesthesia using pentobarbital (doses $0.5 \mathrm{~mL} / \mathrm{kg}$, pentobarbital $60 \mathrm{mg} / \mathrm{mL}$ ), each animal was operated on unilaterally. The goat was positioned on the left side with the right femur fixed. The right leg was shaved and sterilized with Betadine (Mundipharma AG,

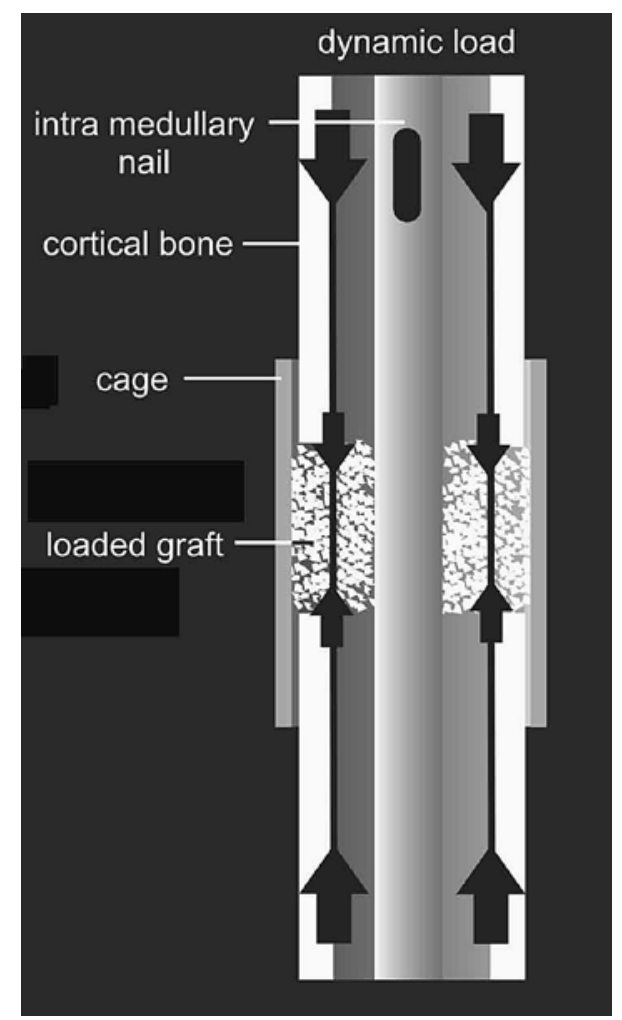

Fig. 1 A schematic representation shows reconstruction with an impacted bone graft. The long slot holes (for screw fixation of the nail) enable dynamic loading of the bone graft. The arrows indicate the route of loading onto the bone graft. 


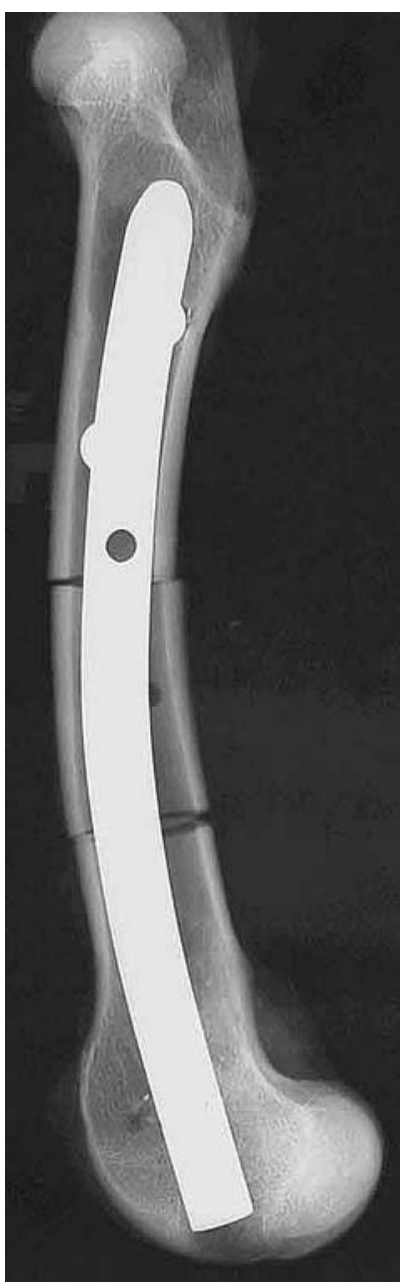

Fig. 2 A direct postoperative radiograph is shown with a segmental defect reconstructed with a structural cortical autograft.

Basel, Switzerland). Using a lateral approach, the femur was exposed through an $8-\mathrm{cm}$ skin incision. The periosteum was opened with a longitudinal incision and bluntly elevated circumferentially with the overlying soft tissues and left in situ. Subsequently, a $3.5-\mathrm{cm}$ segmental defect was created by two osteotomies performed 7 and $10.5 \mathrm{~cm}$ proximal of the lateral joint space line of the knee with an oscillating saw under constant cooling with saline solution. The proximal and distal parts of the femur were marked to prevent rotation malunion. The resected diaphyseal segment of the femur was removed from the operated site in six goats and after 15 minutes placed back in the original position (Fig. 2). In the other six goats, the cortical segment was replaced with a cage filled with morselized impacted bone graft (Fig. 3). The lateral approach was extended with a lateral parapatellar arthrotomy to the knee and the patella was medially subluxated. In the intercondylar femoral notch, the cortex was perforated with a 3-mm drill. With a guide thread, the intramedullary axes were determined. The perforation was enlarged to $11 \mathrm{~mm}$.

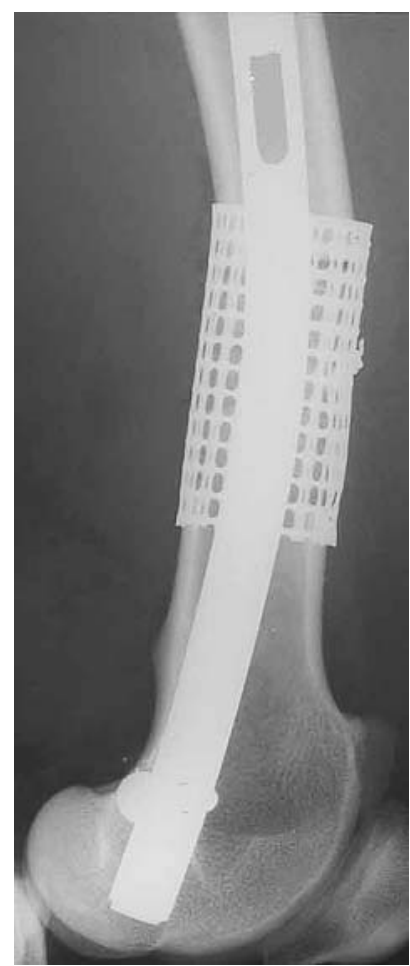

Fig. 3 A direct postoperative radiograph shows a segmental defect, which is reconstructed with an impacted morselized allograft in a cage.

For fixation, a custom-made unreamed femur nail was used. This 16-cm long, 10-mm thick stainless steel nail was bent preoperatively, meeting the average curvature of the goat femur that was measured on lateral radiographs of 40 different goat femurs. The nail was inserted retrograde using the insertion handle connected to the proximal end of the nail. In the group with the massive cortical graft, the nail was locked in a static way by two proximal and two distal screws, thereby following the most commonly applied technique. In the cage group, the nail was dynamically locked to load the bone graft (Fig. 1). The handle with a custom-made aiming device was connected to the proximal end of the nail which avoided the use of an image intensifier for insertion of the nail and AO locking screws (Synthes, Davos, Switzerland). The soft tissues, including the periosteum, were closed over the defect. The knee cavity was irrigated with saline solution to remove blood clots, and the capsule was sutured. Skin wounds were closed intracutaneously. Antibiotic prophylactics consisted of ampicillin subcutaneously administered for 5 days postoperatively (doses $7.5 \mathrm{~mL}$ a day, Albupen $100 \mathrm{mg} / \mathrm{mL}$; Intervet, Boxmeer, The Netherlands).

After the operative procedure, the goats were kept in a hammock for 1 week to prevent postoperative complications and improve wound healing. After the first week, they were allowed unlimited weightbearing. After 2 weeks, the animals were transported from the central animal facility to 
an outdoor farm. Temgesic (Buprenorfine) at a rate of $0.018 \mathrm{~mL} / \mathrm{kg}$ was used as an analgesic three times a day for the first 2 days after surgery and thereafter when necessary. To assess new bone formation on histologic sections, each goat received fluorochromes, a subcutaneous injection of calcein green solution $(20 \mathrm{mg} / \mathrm{kg})$ at 13 weeks postoperatively for 2 days, and alizarin $(30 \mathrm{mg} / \mathrm{kg}$ ) solution for 2 days before the animals were euthanized.

Radiographs were taken 0,12 , and 26 weeks postoperatively using general anesthesia. The lateral and anteroposterior views of the femur were judged (by BS, MWM) for callus formation, alignment, fixation failure, and disappearance of the host bone-graft junction. The gait of the goats was monitored with the score originally developed by Ypma, in which $0=$ not used at all, $1=$ supported incidentally, $2=$ loaded in a standing position and incidentally while walking, $3=$ loaded in a standing position and walking but with a limp, and $4=$ normal walking and standing pattern [21].

After 26 weeks, all goats were euthanized using an injection of $20 \mathrm{~mL}$ of $200 \mathrm{mg}$ na-pentobarbital $/ \mathrm{mL}$ into the jugular vein. The operated and contralateral femora were removed and dissected free from all soft tissues. Our institution approved the animal protocol for this investigation, and all investigations were conducted in conformity with ethical principles of research.

After removal of the nail and screw fixation, biomechanical and histologic analyses were performed on the same specimens. The proximal and distal ends of the operated and contralateral femurs were embedded in acrylic cement (AutoPlast; Candulor AG, Wangen, Switzerland) in such a way that a diaphyseal segment, with the former defect located in the center, was free with a margin of $3 \mathrm{~cm}$ distal and proximal to the former osteotomy site. The specimens were mounted in a Materials Testing System machine (MTS GMBH, Berlin, Germany), in which the distal femur in cement was loaded in external torsion and the proximal cemented end of the femur was fixated except for axial translation. Throughout the experiment, the specimens were kept moist with Ringer's lactate $(0.9 \%)$ at a room temperature of $20^{\circ} \mathrm{C}$. All femora were tested for torsion to failure at a rate of $2^{\circ}$ per second [15]. The parameter chosen to reflect torsion strength was torque at failure. Torsion strength of the operated femur was expressed as a percentage of torque at failure relative to the contralateral, nonoperated femur of the same animal. Therefore, $100 \%$ torsional strength indicated the same strength as the intact case. On the first noticeable crack in the bone, the test was immediately stopped to allow histologic analysis of the whole intact structure.

All specimens were fixed in buffered $(0.1 \mathrm{~mol} / \mathrm{L}$ phosphate buffer, $\mathrm{pH}$ 7.4) paraformaldehyde (4\%) for at least 1 week. Thereafter, at three levels, thick slices were made

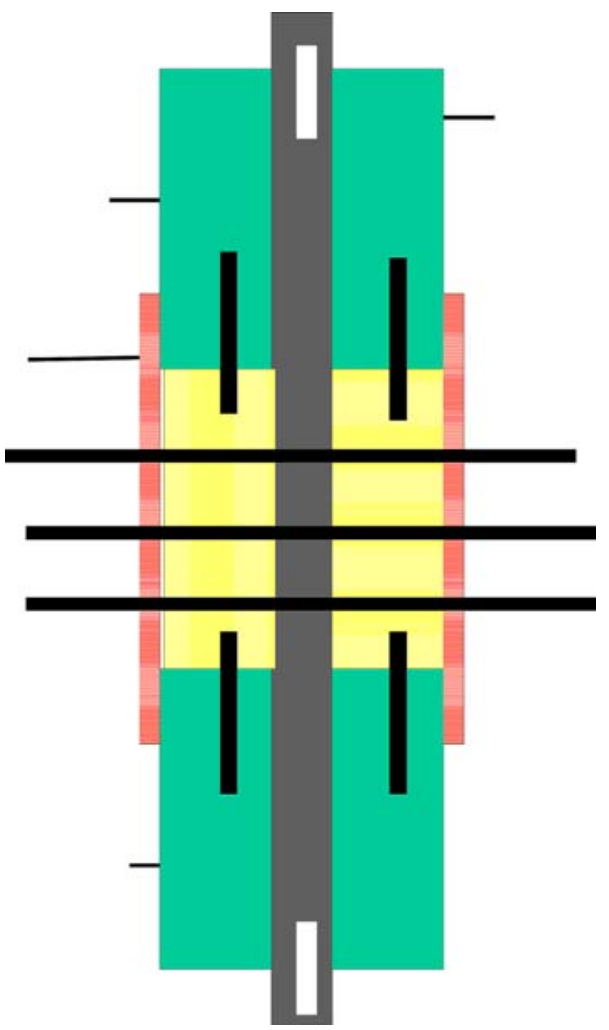

Fig. 4 A schematic representation shows the sectioning planes through the reconstructed segment and through the interface of the reconstruction with the host bone.

for nondecalcified histologic analysis (see Fig. 4 for a schematic representation of the section planes). Of the structural grafts, decalcified histologic analysis was done of adjacent thick slices for quantification of necrosis and bone remodeling. In addition to the cross sections, two $1-\mathrm{cm}$ thick slices were made of the former osteotomy site of the reconstruction with the host bone (Fig. 4). These latter slices were made parallel to the long axis of the bone. All slices were embedded in polymethylmethacrylate. Thin decalcified sections $(7 \mu \mathrm{m})$ were stained with hematoxylin and eosin. Thicker nondecalcified sections $(20-30 \mu \mathrm{m})$ were made with a sawing microtome (Leica SP 1600; Leica Microsystems Nederland BV, Rijswijk, The Netherlands) and left unstained for fluorescence microscopy or stained with hematoxylin and eosin.

All sections from each reconstruction were evaluated (LD, PB) by light microscopy, including fluorescence microscopy, for a qualitative assessment of the incorporation process. The quantification of the total bone area inside and outside the cage (only in the cage group) was performed on three slices at equal distance from each other (spaced approximately $875 \mu \mathrm{m}$ from each other) resulting in one level exactly in the center of the defect and two between the center and osteotomy planes. These cross sections were photographed digitally with an 8-megapixel 
camera at low magnification and mounted in the computer into a composition of the entire slide. With a digital image analysis system (Soft Imaging GmBH, Münster, Germany), the surface area of the bone inside and outside the cage was measured. In addition, the extent of necrosis in the structural graft was quantified. In each cross section, in four images (one in each quadrant) at a magnification of $10 \times$, the surface area of new bone was measured interactively on digitized images and expressed as a percentage of the surface area of the total bone area. In nonstained thick sections, the distance of bone ingrowth was quantified in four locations in each section based on the penetration of fluorescence labels of calcein green (front at 13 weeks) and alizarin (front at 26 weeks). The torsional strength of the four groups (cage reconstruction, cortical graft reconstruction, nonoperated side of the cage group, and nonoperated side of the cortical group) was compared using an analysis of variance test to show differences between groups followed by a post hoc t-test (Tukey).

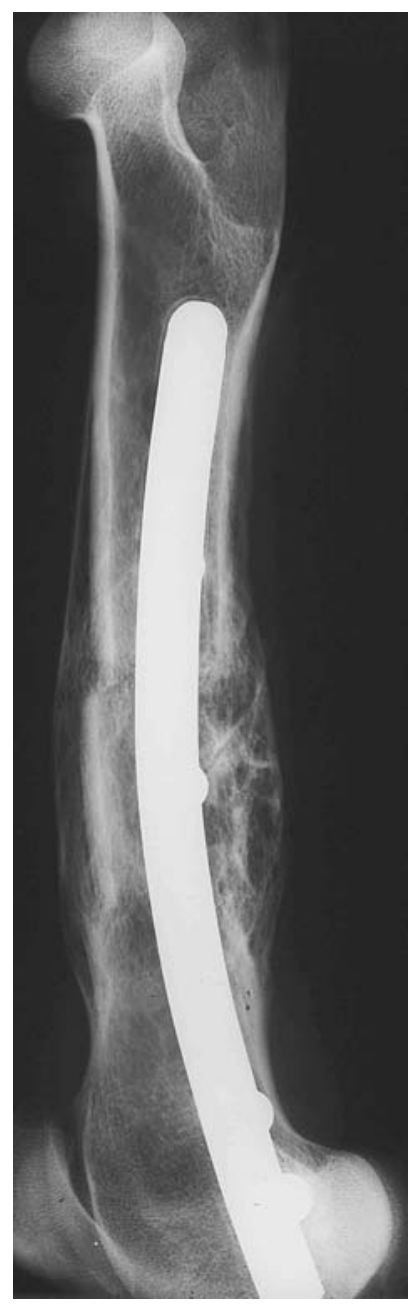

Fig. 5 A radiograph of a structural cortical autograft reconstruction after a followup of 26 weeks shows union of the segment.

\section{Results}

All 12 animals in both intervention groups were mobilized and regained normal gait 2 weeks after mobilization (score of 4$)$.

Radiographically, all goats from both groups achieved consolidation and union (Figs. 5, 6). In all goats, fixation and alignment remained adequate. In the massive cortical group, three goats had a larger intramedullary canal compared with the size of the nail. More bridging callus formation was observed in these goats compared with goats with a smaller femur, in which the nail was more press-fit in the intramedullary canal. In the cage group, five goats showed callus formation directly outside the cage, particularly anteriorly. In one goat with cage reconstruction, there was extensive callus formation around the entire cage and total absence of bone in the cage. The femurs with the cage reconstructions were slightly reduced in height during the postoperative period as could be judged from the changed position of the screw in the slot holes of the nail.

The mean failure torque was similar $(\mathrm{p}=0.77)$ between the reconstructions with cortical graft $(52.8 \pm 14.4 \mathrm{Nm})$ and the impacted graft $(57.5 \pm 9.6 \mathrm{Nm})$. All specimens showed a rather linear pattern on the torque versus angular displacement curves up to the moment of failure (spiral fracture). The mean failure torque of the massive cortical reconstructions and of the cage groups was $60.3 \%$ and

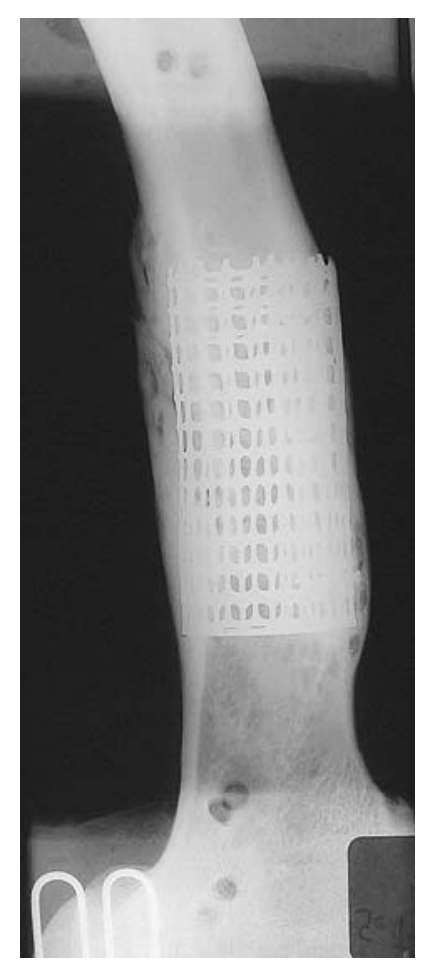

Fig. 6 A radiograph of an impacted morselized graft in a cage after a followup of 26 weeks shows union of the segment. 
$66.6 \%$, respectively, lower than the failure torque of the contralateral femurs $(93.5 \pm 14.8 \mathrm{Nm}$ and $86.9 \pm 5.9 \mathrm{Nm}$; $\mathrm{p}=0.017$ and $\mathrm{p}=0.002$, respectively).

Fluorescence microscopy showed different patterns of incorporation between the structural graft and the impacted morselized graft. In the cortical autograft reconstruction, the original segment was still visible in all sections. The original cortical bone was a mixture of necrotic bone (71.5\%) characterized by empty osteocytes lacunae and new osteons $(28.5 \% \pm 7.5 \%)$ with vital osteocytes (Fig. 7). Based on calcein fluorescence labeling of new bone, the ingrowth distance after 13 weeks was $3783 \pm 1313 \mu \mathrm{m}$, which was $70 \%$ of the thickness of the cortical bone $(5403 \pm 681 \mu \mathrm{m})$. After 26 weeks, the alizarin fluorescence was visible in the peripheral $5154 \pm 655 \mu \mathrm{m}$, which indicated $95.4 \%$ of the cortical bone was revitalized by creeping substitution (Fig. 8). Throughout the new bone in and around the cage group, remodeling sites were stained by calcein green and alizarin. No measurable amount of nonincorporated bone graft was present. The new bone had a normal ultrastructure with fat marrow. In all specimens of the cage group, also, bone had been formed outside the cage. In one cage reconstruction, the new bone was seen predominantly around the cage with almost no bone inside the cage (Fig. 9). The average surface area of bone inside the cage was $50.3 \%$ (range,

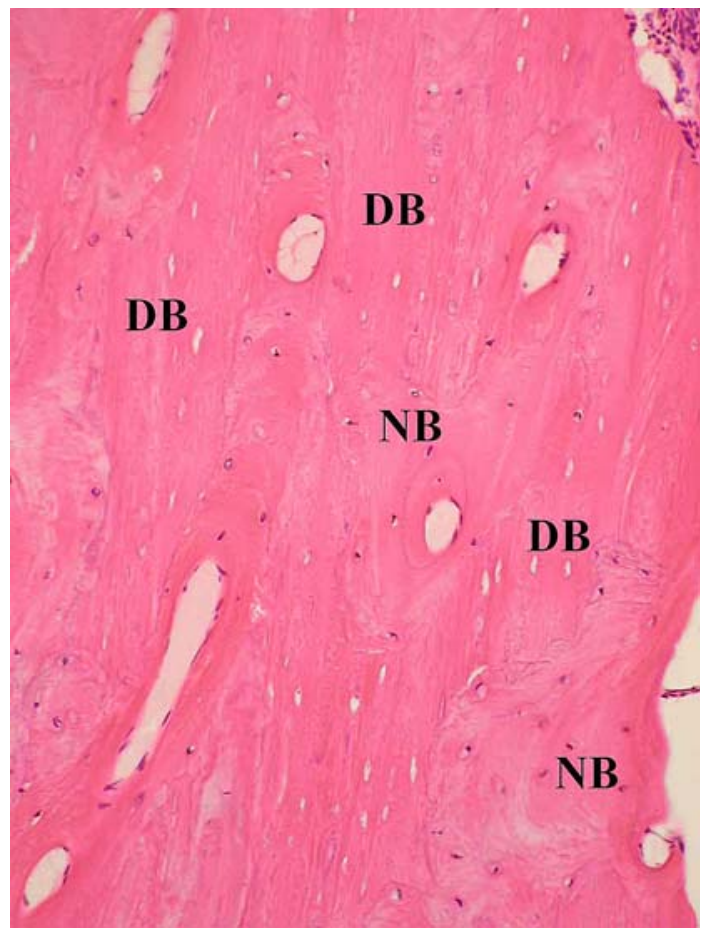

Fig. 7 A section of a reconstruction with a structural cortical autograft after 26 weeks shows a mixture of necrotic dead bone (DB) and new bone (NB) (Stain, hematoxylin and eosin; original magnification, $\times 150)$.

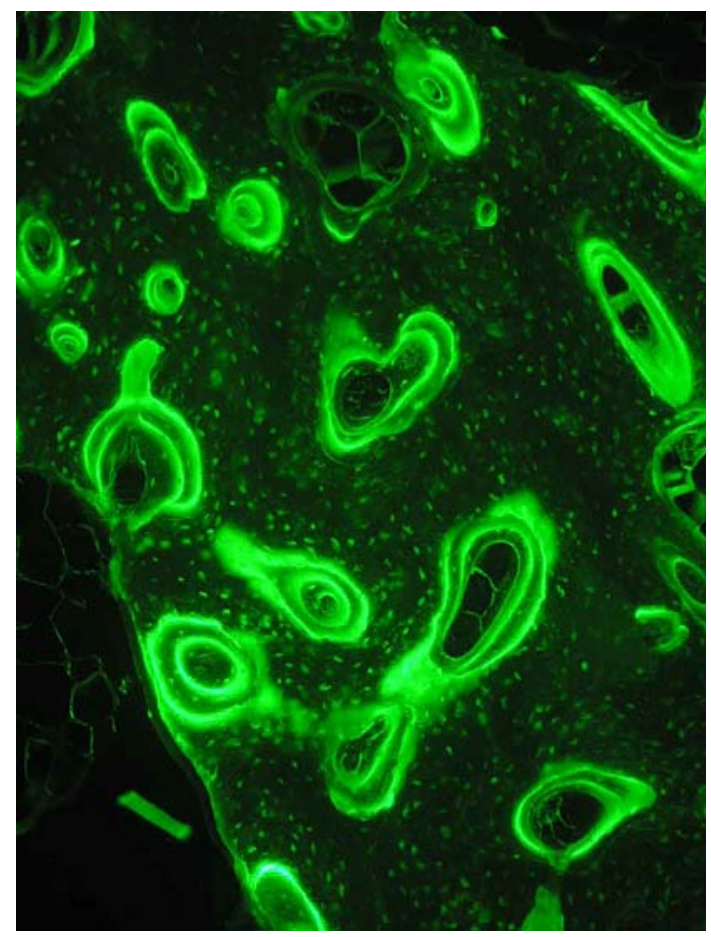

Fig. 8 A section of a structural cortical autograft after 26 weeks shows intense remodeling after labeling with calcein green, which resulted in a mixture of new and necrotic bone (Unstained section, calcein green labeling shown with ultraviolet light; original magnification, $\times 150$ ).

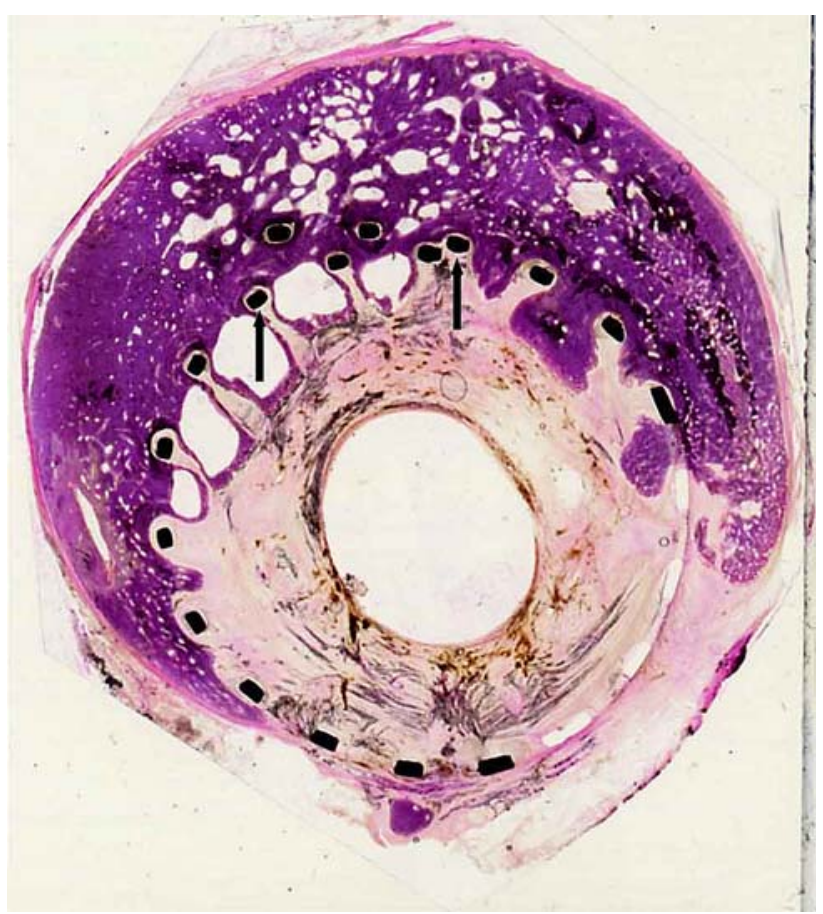

Fig. 9 A sawing section of the reconstruction shows a morselized bone graft after 26 weeks. Newly formed bone is evident outside the mesh (Stain, hematoxylin and eosin; original magnification, $\times 20$ ). 


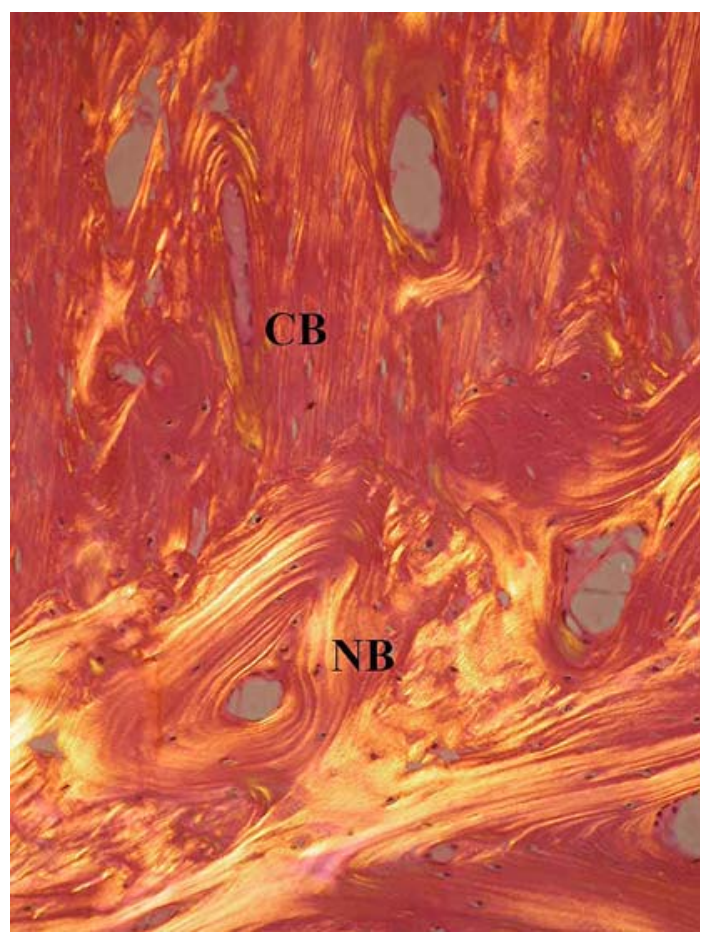

Fig. 10 A hematoxylin and eosin-stained section using polarized light is shown of the transition of cortical bone (CB) and new bone (NB) that had been formed in the gap (Stain, hematoxylin and eosin; original magnification, $\times 150$ ).

$13.1 \%-69.3 \%$ ) of the total surface area of bone inside and outside the cage. In all specimens, the osteotomy gap was completely healed. The gap was completely filled with woven bone that, based on the fluorochrome labels, was remodeling into lamellar bone (Fig. 10).

\section{Discussion}

Large diaphyseal bone defects resulting from trauma, osteomyelitis, or resection of bone tumors often require reconstruction. In many of these situations structural allografts are used for large defections. However, massive cortical allografts are associated with various complications including nonunion, infection, and fatigue fractures $[2,11,20]$. We compared reconstructions of large segmental diaphyseal bone defects in goats with a structural autograft to reconstruction with impacted morselized bone graft. We focused on the clinical performance, on the radiographic healing, on the mechanical properties of the reconstructions, and on the histologic appearance of the two graft types.

This study has some limitations. In goats, the height of the defect was $3.5 \mathrm{~cm}$, which is a critically sized defect, but only approximately $20 \%$ of the length of the goat femur. In patients, larger reconstructions of as much as 15 to $20 \mathrm{~cm}$ are performed regularly, which will influence the primary stability and possibly limit the use of this technique. Moreover, in patients, the healing capacity will be compromised by trauma, resection of the periosteum, or adjuvant therapy, and the fit of particularly the structural graft may be less optimal than in this study [8]. The number of goats in this study was rather low which did not allow any conclusions regarding differences between impacted graft and structural graft. Finally, goats may not show any discomfort after a surgical procedure because this would make them vulnerable to predators and they may walk effectively on three limbs. Therefore the loading patterns in goats are less informative compared with bipedal humans.

The radiographic unions in all goats matched the torsion tests because all femurs had torsion strength on the order of $60 \%$, whereas the torsion strength of nonunions is reportedly approximately $20 \%$ [9]. Relative to allografts, autografts have generally superior biologic properties, which may have contributed to the optimal union with the host bone in the structural graft group [32]. The location of callus in the cage group was different from the callus around the structural grafts. In the cage, more bone was formed ventrally outside the cage. Probably this is an effect of the changed loading conditions during the initial phase of the incorporation process, in which the ventral part is probably more loaded than the dorsal part. This might have induced a callus outside the mesh at this location. After the formation of this new bone, stress shielding by the bone and by the load transmitted through the mesh, which is in this stage intimately connected with the bone, might have been responsible for the formation of an osteopenic area in the dorsocentral part inside the cage [20, 21, 24].

The radiographs of structural graft specimens showed the callus formation appeared directly related to the width of the intramedullary canal. Although small allograft chips were used to facilitate filling of the small space between the graft and the nail, in three goats with a wider intramedullary canal, the fit of the nail directly postoperatively was less optimal and this has led to more callus formation. Fracture healing studies suggest unstable fractures induce more callus $[12,16]$. The callus thus might be induced by instability and resulting micromotion during the healing period. These results show the importance of a perfect fit of the central rod in the femoral canal. For the future, clinical well-fitting or custom-made nails are advocated.

Another option to provide more stability is to add an extra rigid fixation plate, which might lead to better healing [3]. The segmental diaphyseal defect may have been fixed with such an external plate, but screws then have to be inserted in necrotic bone and screw holes act as stress risers in these cases [33]. Therefore, a locking nail concept seemed the best choice. 
The major clinical difference with revision arthroplasty is the direction of the load applied on the graft. The load in revision arthroplasty is induced by a subsiding conicalshaped stem, which generates mainly hoop and compressive stresses in the graft. In the segmental reconstruction, the dynamized fixation of the intramedullary nail results in primarily compressive stress in the graft material. As all goats survived the study period well, our experience suggests initial stability was adequate for direct load-bearing. The load may have had a beneficial effect on the incorporation process. Moreover, the stem in revision hip arthroplasty is fixated in the graft reconstruction. In reconstruction of a segmental diaphyseal bone defect, the central rod has the same function as the stem in a revision situation but is fixed proximally and distally, which will reduce the bending forces in the graft material as compared with the hip situation.

The torsion strength of the massive cortical graft and cage reconstruction appeared to be $60 \%$ and $67 \%$ of the normal value after 6 months, respectively. As a result of the limited number of animals included in this study, we were unable to show differences between the two groups. Segmental defects in other animal models reconstructed with cortical autografts reportedly regained $50 \%$ in torsion strength after 6 months and nearly normal torsion strength after 1 year $[9,10]$. The observations in these studies are in concordance with the results in our model.

The incorporation pattern in the structural graft was similar to that published for dogs [10]. In our study, approximately $20 \%$ of the necrotic bone was revitalized by creeping substitution. In dogs, remodeling of $60 \%$ of a cortical fibula autograft was found after 1 year [10]. In patients, massive cortical human allografts reportedly unite slowly and more periosteal bone is formed than internally repaired, which was only $20 \%$ of the graft by 5 years. However, this relatively slow revitalization probably is compromised by therapies for the disease process [11].

Although the porosity of the morselized graft will decrease during impaction, it still is less dense than the structural cortical graft [6]. The relative open structure of the cages and the impacted bone graft facilitate ingrowth and revascularization in large bone defects [5]. Resorption of morselized bone graft is followed in all animal models by replacement of new bone. In the cage group, the original graft was resorbed completely and replaced by new bone, which is in concordance with previous studies in which morselized bone grafts in reconstructions remodel into healthy bone if applied under loaded conditions [17, 24, 25, $34,35]$. A retrieval analysis of failed cage reconstructions, in which the morselized bone was stress-shielded by the design of the cage, showed only $30 \%$ viable bone in the cages [30]. In the long term, it seems necessary to load the morselized bone grafts to induce new bone with optimal quantity and quality [34]. In our model, this load was applied continuously by the locking nails, which did not reach the end of their dynamization stage. Load theoretically could lead to micromotions at the implant-bone interface during the remodeling phase. However, two longterm reports describing reconstructions with loaded morselized graft around a hip implant show very favorable results, which suggests that micro-motions are not large enough to be detrimental $[14,26]$.

Our data showed a cage filled with impacted morselized graft was adequate to reconstruct and heal a segmental diaphyseal bone defect in a goat femur allowing full weightbearing. The reconstruction of segmental diaphyseal bone defects using a cage with a morselized graft had better biologic characteristics compared with a structural cortical autograft. The mechanical properties after incorporation were not different. A cage filled with a mechanically loaded morselized graft is a promising alternative for the massive cortical graft in reconstruction of large diaphyseal defects in an animal model.

Acknowledgments We thank Leon Driessen and Willem van de Wijdeven for technical assistance.

Open Access This article is distributed under the terms of the Creative Commons Attribution Noncommercial License which permits any noncommercial use, distribution, and reproduction in any medium, provided the original author(s) and source are credited.

\section{References}

1. Arts JJ, Gardeniers JW, Welten ML, Verdonschot N, Schreurs BW, Buma P. No negative effects of bone impaction grafting with bone and ceramic mixtures. Clin Orthop Relat Res. 2005;438:239-247.

2. Bauer TW, Muschler GF. Bone graft materials: an overview of the basic science. Clin Orthop Relat Res. 2000;371:10-27.

3. Beardi J, Hessmann M, Hansen M, Rommens PM. Operative treatment of tibial shaft fractures: a comparison of different methods of primary stabilisation. Arch Orthop Trauma Surg. 2008;128:709-715.

4. Board TN, Rooney P, Kearney JN, Kay PR. Impaction allografting in revision total hip replacement. J Bone Joint Surg Br. 2006;88:852-857.

5. Bolder SB, Schreurs BW, Verdonschot N, Veth RPH, Buma P. Wire mesh allows more revascularization than a strut in impaction bone grafting: an animal study in goats. Clin Orthop Relat Res. 2004;423:280-286.

6. Bonutti PM, Cremens MJ, Miller BG. Formation of structural grafts from cancellous bone fragments. Am $J$ Orthop. 1998;27:499-502.

7. Buma P, Lamerigts N, Schreurs BW, Gardeniers J, Versleyen D, Slooff T. Impacted graft incorporation after cemented acetabular revision: histological evaluation in 8 patients. Acta Orthop Scand. 1996;67:536-540.

8. Deijkers RL, Bloem RM, Kroon HM, van Lent JB, Brand R, Taminiau AHM. Epidiaphyseal versus other intercalary allografts for tumors of the lower limb. Clin Orthop Relat Res. 2005;439:151-160. 
9. Den Boer FC, Patka P, Bakker FC, Wippermann BW, van Lingen A, Vink GQM, Boshuizen K, Haarman HJ. New segmental long bone defect model in sheep: quantitative analysis of healing with dual energy x-ray absorptiometry. J Orthop Res. 1999;17:654-660.

10. Enneking WF, Burchardt H, Puhl JJ, Piotrowski G. Physical and biological aspects of repair in dog cortical-bone transplants. J Bone Joint Surg Am. 1975;57:237-252.

11. Enneking WF, Mindell ER. Observations on massive retrieved human allografts. J Bone Joint Surg Am. 1991;73:1123-1142.

12. Epari DR, Schell H, Bail HJ, Duda GN. Instability prolongs the chondral phase during bone healing in sheep. Bone. 2006;38: 864-870.

13. Garcia-Cimbrelo E, Marti-Gonzalez JC. Circular external fixation in tibial nonunions. Clin Orthop Relat Res. 2004;419:65-70.

14. Gie GA, Linder L, Ling RS, Simon JP, Slooff TJJH, Timperly AJ. Impacted cancellous allografts and cement for revision total hip arthroplasty. J Bone Joint Surg Br. 1993;75:14-21.

15. Keijser LC, Schreuder HW, Boons HW, Keulers BJ, Buma P, Huiskes R, Veth RP. Bone grafting of cryosurgically treated bone defects: experiments in goats. Clin Orthop Relat Res. 2002; 396:215-222.

16. Klein P, Schell H, Streitparth F, Heller M, Kassi JP, Kandziora F, Bragulla H, Haas NP, Duda GN. The initial phase of fracture healing is specifically sensitive to mechanical conditions. J Orthop Res. 2003;21:662-669.

17. Lamerigts NM, Buma P, Huiskes R, Gardeniers J, Schreurs W, Slooff TJ. Incorporation of morsellized bone graft under controlled loading conditions: a new animal model in the goat. Biomaterials. 2000;21:741-747.

18. Mckee MD, Yoo D, Schemitsch EH. Health status after Ilizarov reconstruction of post-traumatic lower-limb deformity. $J$ Bone Joint Surg Br. 1998;80:360-364.

19. Mekhail AO, Abraham E, Gruber B, Gonzalez M. Bone transport in the management of posttraumatic bone defects in the lower extremity. J Trauma. 2004;56:368-378.

20. Muscolo DL, Ayerza MA, Ponte-Tinao LA. Massive allograft use in orthopedic oncology. Orthop Clin North Am. 2006;37:65-74.

21. Schimmel JW, Buma P, Versleyen D, Huiskes R, Slooff T. Acetabular reconstruction with impacted morselized cancellous allografts in cemented hip arthroplasty: a histological and biomechanical study on the goat. J Arthroplasty. 1998;13:438-448.

22. Schreurs BW, Arts JJ, Verdonschot N, Buma P, Slooff TJ, Gardeniers JW. Femoral component revision with use of impaction bone-grafting and a cemented polished stem. $J$ Bone Joint Surg Am. 2005;87:2499-2507.

23. Schreurs BW, Arts JJ, Verdonschot N, Buma P, Slooff TJ, Gardeniers JW. Femoral component revision with use of impaction bone-grafting and a cemented polished stem: surgical technique. J Bone Joint Surg Am. 2006;88(suppl 1):259-274.

24. Schreurs BW, Buma P, Huiskes R, Slagter JL, Slooff T. Morselized allografts for fixation of the hip-prosthesis femoral component: a mechanical and histological study in the goat. Acta Orthop Scand. 1994;65:267-275.

25. Schreurs BW, Huiskes R, Buma P, Slooff TJJH. Biomechanical and histological evaluation of a hydroxyapatite-coated titanium femoral stem fixed with an intramedullary morselized bone grafting technique: an animal experiment on goats. Biomaterials. 1996;17:1177-1186.

26. Schreurs BW, Slooff TJJH, Gardeniers JWM, Buma P. Acetabular reconstruction with bone impaction grafting and a cemented cup: 20 years' experience. Clin Orthop Relat Res. 2001;393:202-215.

27. Schreurs BW, van Tienen TG, Buma P, Verdonschot N, Gardeniers JW, Slooff TJ. Favorable results of acetabular reconstruction with impacted morselized bone grafts in patients younger than 50 years: a 10- to 18-year follow-up study of 34 cemented total hip arthroplasties. Acta Orthop Scand. 2001;72:120-126.

28. Sporer SM, O'Rourke M, Chong P, Paprosky WG. The use of structural distal femoral allografts for acetabular reconstruction: average ten-year follow-up. J Bone Joint Surg Am. 2005;87: 760-765.

29. Sporer SM, O'Rourke M, Chong P, Paprosky WG. The use of structural distal femoral allografts for acetabular reconstruction: surgical technique. J Bone Joint Surg Am. 2006;88(suppl 1): 92-99.

30. Togawa D, Bauer TW, Lieberman IH, Lowery GL, Takikawa S. Histology of tissues within retrieved human titanium mesh cages. Spine. 2003;28:246-253.

31. van der Donk S, Buma P, Slooff TJ, Gardeniers J, Schreurs BW. Incorporation of morselized bone grafts: a study of 24 acetabular biopsy specimens. Clin Orthop Relat Res. 2002;396:131-141.

32. van der Donk S, Weernink T, Buma P, Aspenberg P, Slooff TJ, Schreurs BW. Rinsing morselized allografts improves bone and tissue ingrowth. Clin Orthop Relat Res. 2003;408:302-310.

33. van der Griend RA. The effect of internal fixation on the healing of large allografts. J Bone Joint Surg Am. 1994;76:657-663.

34. van Loon CJ, Buma P, de Waal Malefijt MC, van Kampen A, Veth RP. Morselized bone allografting in revision total knee replacement: a case report with a 4-year histological follow-up. Acta Orthop Scand. 2000;7:98-101.

35. van Loon CJ, de Waal Malefijt MC, Buma P, Stolk T, Verdonschot N, Tromp AM, Huiskes R, Barneveld A. Autologous morsellised bone grafting restores uncontained femoral bone defects in knee arthroplasty: an in vivo study in horses. J Bone Joint Surg Br. 2000;82:436-444. 